\title{
PROJETO DE EXTENSÃO: AS CONTRIBUIÇÕES PARA O ALCANCE DA AGENDA 2030 PARA O DESENVOLVIMENTO SUSTENTÁVEL
}

\section{EXTENSION PROJECT: CONTRIBUTIONS TO THE ACHIEVEMENT OF THE 2030 AGENDA FOR SUSTAINABLE DEVELOPMENT}

\author{
Nájila Rejanne Alencar Julião Cabral* \\ ORCID: http://orcid.org/0000-0003-0960-9587 \\ Maria de Lourdes da Silva Neta** \\ ORCID: https://orcid.org/0000-0002-3726-4806 \\ Adeildo Cabral da Silva**** \\ ORCID: http://orcid.org/0000-0002-5433-6437
}

\section{Resumo}

O objetivo deste artigo foi analisar as ações de educação ambiental executadas no âmbito da extensão por alunos e professores do IFCE, no período de 2015 a 2019, desenvolvidas no Projeto Casa Maranguape, com relação à adoção dos Objetivos do Desenvolvimento Sustentável (ODS) da Agenda 2030. Esta investigação teve abordagem qualitativa e pautou-se em pesquisa documental, com técnica de análise de conteúdo de dados, descrita por Silva e Fossá (2015). Os contextos educacionais enfatizaram a ação extensionista e sua contribuição para o alcance dos ODS. Os resultados mostram abordagem em educação ambiental de 67\% das atividades, com aderência de 11 entre os 17 ODS, demonstrando interdisciplinaridade com a Agenda 2030. Quanto à contribuição à prática docente, observaram-se o compromisso social da Instituição e a realização da missão fundamental da extensão, que é dar respostas à sociedade, além da aquisição de saberes experimentais voltados ao desenvolvimento local sustentável.

Palavras-chave: Casamar; Extensão; Sustentabilidade; IFCE

\begin{abstract}
This paper aimed to analyze the environmental education actions performed in extension projects by the IFCE (Federal Institute of Ceara) by students and teachers, in the period from 2015 to 2019, developed in the Casa Maranguape Project, with respect to the adoption of the Sustainable Development Goals (SDGs) of the 2030 Agenda. This research had a qualitative approach and was based on document research with the data content analysis technique described by Silva; Fossá (2015). The educational contexts emphasized the extensionist action and its contribution to the SDGs achievement. The results show an approach towards environmental education in $67 \%$ of the activities, with adherence of 11 among the 17 SDGs, demonstrating interdisciplinarity with the 2030 Agenda. As for the contribution to the teaching practice, the social commitment of the institution was observed along with the achievement of the extension fundamental mission, which is to provide answers to society, in addition to the acquisition of experimental knowledge aiming at sustainable local development.
\end{abstract}




\section{Introdução}

A sociedade é formada por pessoas únicas, singulares, em constante processo de elaboração de saberes, conhecimentos, competências e habilidades. Para auxiliar nesse desempenho de construção da cidadania, da formação humana e da formação profissional, as instituições de ensino desempenham papel fundamental por serem os lócus de ensino formal, notadamente as instituições de Educação Profissional e Tecnológica, a exemplo dos Institutos Federais de Educação, Ciência e Tecnologia.

Nos Institutos Federais, a educação aborda uma tríade formada pelo ensino, pesquisa e extensão, que viabiliza o conjunto de práticas pedagógicas que se apoiam nas teorias e práticas e que respeitam concepções de aprendizagem apoiadas em dois fundamentos: o de que todo conhecimento provém da prática social e a ela retorna; e o de que o conhecimento é um empreendimento coletivo (GIUSTA, 2013).

O aprendizado, para ser profícuo, deve englobar aspectos institucionais, experimentais, práticos, curriculares, numa vivência que vincule a formação e o crescimento pessoal e profissional do aprendiz. Assim, os saberes disciplinares, curriculares e experienciais comentados por Tardif (2014) impulsionam o espaço escolar e favorecem a dinâmica do aprendizado. O saber docente é plural e estratégico, conforme Tardif (2014), tendo o ensino, a pesquisa científica e a extensão como produções de conhecimento solidárias ao sistema de formação.

O objetivo desta pesquisa foi avaliar a importância da realização de ações de extensão para a territorialização dos Objetivos do Desenvolvimento Sustentável em nível local. A escolha do estudo de caso do programa de extensão, o Projeto Casa Maranguape (Projeto Casamar), ocorreu em virtude de este projeto estar sendo desenvolvido no Departamento da Construção Civil (DCC), do Instituto Federal de Educação, Ciência e Tecnologia do Ceará (IFCE). Apesar de ter o nome Projeto Casamar, constitui-se em um programa, em virtude de programas terem horizonte temporal de média duração e atenderem aos objetivos de planos. $\mathrm{O}$ citado projeto existe há 16 anos, tendo sido implementado por meio do Convênio SEMADE $\mathrm{n}^{\mathrm{o}} 001 / 2004$. No caso do objeto de estudo deste artigo, o programa "Projeto Casamar" atende aos planos político pedagógicos dos cursos do DCC/IFCE.

Justifica-se estudar o compromisso do Projeto Casamar com os Objetivos do Desenvolvimento Sustentável (ODS) em razão deste programa de extensão estar vinculado às atividades extracurriculares de ensino e, também, por sua potencial contribuição para o exercício da prática docente com relação às ações que envolvam as questões ambientais.

Justificam-se, ainda, pelo fato de o Projeto Casamar vir sendo o alvo das intervenções de ações de extensão em diferentes semestres ao longo dos anos, desde 2004. Temas como educação ambiental, reaproveitamento de resíduos sólidos e transferência de tecnologia de elementos construtivos são algumas temáticas que já foram executadas no Projeto Casamar, ao longo de quase 17 anos de sua existência e resistência.

Assim, entende-se que o estudo de caso de ações de educação ambiental de um programa de extensão, cuja intervenção se dá em uma comunidade de vulnerabilidade social, incorpora 
as dimensões da sustentabilidade e, provavelmente, auxilia na consecução dos Objetivos do Desenvolvimento Sustentável (ODS) preconizados pela Agenda 2030.

O projeto Casa Maranguape é parte integrante das atividades de extensão do Instituto Federal do Ceará. O Instituto Federal do Ceará está comprometido com uma educação em sintonia com as demandas sociais, econômicas e culturais da sociedade atual, permeando-se as questões de diversidade cultural e de preservação ambiental, pautando-se na ética, na responsabilidade e no cuidado, conforme estabelece o Projeto Político Institucional (PPI), aprovado pela Resolução CONSUP $n^{\circ} 33$, de 2015. Ainda conforme o PPI, a extensão é uma práxis que possibilita o acesso aos saberes produzidos e experiências acadêmicas, oportunizando, dessa maneira, o usufruto direto e indireto, por parte de diversos segmentos sociais (IFCE, 2015; 2018).

O Instituto Federal do Ceará diz, textualmente, em seu Plano Estratégico de Permanência e Êxito 2017-2024 (PPE), que

[...] é relevante o reforço de ações que provoquem a participação dos estudantes em atividades de ensino, pesquisa e extensão e que possibilitem aos estudantes um percurso exitoso de formação acadêmica e profissional, no sentido de garantir reais condições de permanência (IFCE, 2017, p.2).

O PPE admite que, dentre os fatores institucionais de ordem pedagógica ou administrativa que influenciam direta ou indiretamente no processo de evasão e de retenção, estão as poucas iniciativas no estímulo à realização de pesquisa e de extensão (IFCE, 2017, p. 27), o que reforça a importância de se estudarem as ações de um programa de extensão e seu compromisso como auxílio à permanência e êxito (formação) dos jovens.

A escola é, ou deveria ser, o ambiente favorável para a construção do conhecimento do ser humano, em seu aspecto de formação para a vida pessoal e profissional. $O$ tratamento pedagógico e diversificado que a Educação Profissional e Tecnológica (EPT) permite - a exemplo da formação omnilateral para compreensão do mundo do trabalho - reconhecer e valorizar a pluralidade e as diferenças individuais e coletivas, na intenção de preparar o estudante para o trabalho e para a sociedade. As políticas delineadas sobre a educação profissional após a Constituição de 1988, tratadas em seu artigo 213, considerando atividades de pesquisa, de extensão e de estímulo à inovação, se aproximam, também, do que Alves (2009) chamou de "escolas que são asas", que "existem para dar aos pássaros (estudantes) coragem para voar".

Esse novo fazer ou a inovação do trabalho pedagógico, segundo Masetto (2010), incorpora o estabelecimento de quatro objetivos a serem alcançados na aprendizagem: quanto à organização dos conteúdos, à seleção das estratégias, ao processo de avaliação e à postura do docente. Esse conjunto confere uma emancipação social aos estudantes. O citado autor ressalta a importância da mediação pedagógica no processo ensino/aprendizagem exercida pelo docente como facilitador e incentivador. Esse comportamento docente, exercido na tríade ensino, pesquisa e extensão, colabora para que o aprendiz alcance seus objetivos. 
Colocar em prática essa inovação constitui um desafio emergente e atual, que pode representar um projeto de política comum, a ser pensado para ser desenvolvido pelas escolas profissionais de nível federal, os Institutos Federais, uma vez que eles atuam, verdadeiramente, como veículos de promoção de uma educação integrada, com consequente interveniência na diminuição das desigualdades do País, exercendo uma educação com formação integral, interdisciplinar e com flexibilidade.

No caso do IFCE, a Lei n. ${ }^{\circ} 11.892 / 2008$, em seu art. $7^{\circ}$, define que faz parte de seus objetivos o desenvolvimento de atividades de extensão de acordo com os princípios e finalidades da educação profissional e tecnológica. Conceitualmente, extensão é ação interdisciplinar, indissociável do ensino e da pesquisa, uma responsabilidade social das instituições formativas, que assume papel fundamental na produção e socialização dos conhecimentos, cujo desenvolvimento tem como principal público-alvo a comunidade externa do campus, o que não impede a participação da comunidade acadêmica (IFCE, 2018, p. 109). As atividades de extensão são consideradas complementares ao percurso curricular, com o intuito de contribuir para o crescimento social, profissional e o desenvolvimento da autonomia do estudante (IFCE, 2018, p. 54), como também visam atuar na produção e construção de saberes docentes voltados para o desenvolvimento social, equitativo, sustentável, atualizado e coerente com a realidade brasileira (IFCE, 2018, p.112).

As atividades de extensão constituem um elemento aglutinador ao processo de aprendizagem, estando em sintonia com as demandas sociais, econômicas e culturais, permitindo a prática de interdisciplinaridade e flexibilidade inerentes à formação integral e integrada com o direito à dignidade da vida humana.

No âmbito da extensão, o Departamento da Construção Civil do IFCE, por meio do Laboratório de Energias Renováveis e Conforto Ambiental (LERCA), desenvolve o Projeto Casa Maranguape (Projeto Casamar). Cabral e Silva (2018) informam que o propósito do Projeto Casamar é colaborar com políticas públicas voltadas à melhoria de qualidade de vida, por meio de ações de extensão em educação ambiental, em inclusão social, em transferência de tecnologias construtivas e outras. A Comunidade Villares da Serra, local do Projeto, tem cerca de 800 pessoas entre crianças, adolescentes, jovens e idosos, as quais o definem o público-alvo das intervenções de extensão em diferentes semestres, sendo extensionistas os professores e os alunos oriundos dos cursos de graduação e de pós-graduação do IFCE (SILVA; CABRAL, 2019).

A cada semestre, estudantes do IFCE de diferentes níveis e modalidades de ensino participam das ações de extensão no Projeto Casamar, configurando-se numa oportunidade interessante de aplicarem os conhecimentos adquiridos nos diferentes cursos em uma comunidade carente no município de Maranguape, a Comunidade Villares da Serra.

Sobre a gestão e organização das ações educativas para a inclusão social, na avaliação de Silva e Cabral (2012), destaca-se nestas ações a disciplina Projetos Sociais, do IFCE, ofertada para todos os cursos dos níveis de graduação e de pós-graduação Lato e Stricto Sensu, na qual são discutidas temáticas direcionadas à formação ética e cidadã. Os autores citados comentam que as ações têm intervenção em comunidades de baixa renda, permitindo 
aos alunos uma compreensão crítica da realidade, sua responsabilidade nas questões socioambientais e seu comprometimento político social, enquanto cidadãos responsáveis pelas questões inerentes a sua comunidade, cidade e país.

Ao se falar em questões socioambientais e em sustentabilidade, há de se destacar as agendas de desenvolvimento firmadas como compromissos pelos países que integram a Organização das Nações Unidas, inclusive o Brasil. O mais recente pacto, a Agenda 2030, estabelece horizonte temporal de consecução dos Objetivos do Desenvolvimento Sustentável (ODS) entre 2015 e 2030, e traz 169 metas para os 17 diferentes ODS, com necessária interlocução e participação dos diferentes setores da sociedade. Autores como Hák et al. (2016), Biermann et al. (2017) e Menezes (2018) relatam sobre a importância das metas como estratégia-chave e do potencial que os ODS têm em todos os segmentos da sociedade civil.

O Brasil alinhou seus objetivos nacionais aos ODS em um esforço que envolveu 75 órgãos governamentais e centenas de gestores e técnicos do Governo Federal, que participaram dos debates e enviaram sugestões a serem incorporadas às metas nacionais. $\mathrm{O}$ resultado desse processo participativo foi o documento "Agenda 2030 ODS - metas nacionais dos Objetivos do Desenvolvimento Sustentável", que permite o acompanhamento considerando-se as características e especificidades das prioridades nacionais para a devida implementação das políticas públicas requeridas, nas suas três esferas: União, estados e municípios, consoante os compromissos assumidos pelo Brasil (IPEA, 2018). Resumidamente, do total de 169 metas globais encaminhadas pela Organização das Nações Unidas (ONU), 167 foram consideradas pertinentes ao país, ainda que muitas delas tenham requerido alterações no texto para se adequarem às especificidades nacionais (IPEA, 2018). Foram criadas 8 novas metas, totalizando 175 metas nacionais, das quais 99 foram classificadas como finalísticas e 76 como de implementação (IPEA, 2018).

A Agenda 2030 constitui-se em um plano de ação ousado para enfrentar os problemas existentes, que possa conduzir pessoas, por meio de parcerias colaborativas, ao alcance da prosperidade, para alcançar um mundo sustentável e de paz, comprometendo-se a não deixar ninguém para trás (PNUD, 2019).

Os Objetivos do Desenvolvimento Sustentável (ODS) estão compostos da seguinte maneira: ODS 1 - erradicação da pobreza; ODS 2 - fome zero e agricultura sustentável; ODS 3 - saúde e bem-estar; ODS 4 - educação de qualidade; ODS 5 - igualdade de gênero; ODS 6 - água potável e saneamento; ODS 7 - energia limpa e acessível; ODS 8 - trabalho decente e crescimento econômico; ODS 9 - indústria, inovação e infraestrutura; ODS 10 - redução de desigualdades; ODS 11 - cidades e comunidades sustentáveis; ODS 12 - consumo e produção responsável; ODS 13 - ação contra mudança global do clima; ODS 14 - vida na água; ODS 15 - vida terrestre; ODS 16 - paz, justiça e instituições eficazes e ODS 17 parcerias e meios de implementação (ONU, 2015).

A Comissão Nacional para os Objetivos do Desenvolvimento Sustentável entendeu que a comunicação e a disseminação são estratégias complementares, devendo estar em um único plano, o Plano de Disseminação da Agenda 2030, para atingir todo território nacional (CNODS, 2018). Faz parte deste plano a internalização da Agenda 2030 e de ações relacionadas 
ao alinhamento das políticas públicas federais com os ODS e ao fortalecimento de parcerias com a sociedade civil e com todos os atores sociais, inclusive instituições de ensino (CNODS, 2018).

A sociedade civil precisa estar atenta, acompanhando o cenário atual político e econômico brasileiro, à luz dos desafios de se implementar a Agenda 2030. O IDS (2019) externa a preocupação com políticas públicas que podem afastar o Brasil de um futuro sustentável, o que exige forte atuação das instituições fiscalizadoras nacionais e alinhamento dos governos locais e do parlamento aos ODS. Dentre as recomendações do III Relatório Luz da Agenda 2030 de Desenvolvimento Sustentável, estão: garantir o direito à educação para todos como um bem público, com qualidade socialmente referenciada e efetivar um intenso processo de Educação Ambiental que dialogue com a sociedade, esclareça e guie as ações de implementação da Agenda 2030 (IDS, 2019).

Os desafios são muitos e há urgência em se mapear o conjunto de iniciativas e ações que visam a incorporar os ODS na agenda do desenvolvimento local. A territorialização e localização da Agenda 2030 têm sido objeto de programas de capacitação pelo PNUD, no sentido de promover o monitoramento e avaliação de políticas públicas locais (PNUD, 2020).

\section{Metodologia}

Esta investigação teve abordagem qualitativa e pautou-se em pesquisa documental (relatórios discentes e arquivos do PNUD). Para Minayo (2004), na abordagem qualitativa o pesquisador participa, compreende e interpreta os eventos sociais de sua pesquisa.

Considerando o objetivo de analisar as ações de educação ambiental desenvolvidas no Projeto Casa Maranguape, com relação à adoção dos Objetivos do Desenvolvimento Sustentável, no período de 2015 a 2019, os sujeitos participantes que tiveram suas ações analisadas foram alunos oriundos da disciplina Projetos Sociais, dos cursos de Tecnologia em Saneamento Ambiental e do Bacharelado em Engenharia Civil do IFCE.

A coleta de dados abrangeu o período de 2015 a 2019, em virtude de os ODS terem início em 2015 e, como a base de dados foi secundária, optou-se por encerrar o período de coleta em 2019. A importância dos ODS diz respeito ao compromisso mundial firmado por países em torno de uma agenda positiva de desenvolvimento, que promove a equidade social, a prudência ecológica e a viabilidade econômica (BRASIL, 2017).

É preciso atentar que, nos Projetos Político Pedagógicos (PPP) dos cursos do Departamento da Construção Civil (DCC), existe a estrita observância aos preceitos determinados na Resolução CNE $n^{0}$ 2, de 15 de junho de 2012, que estabelece as Diretrizes Curriculares Nacionais para a Educação Ambiental (BRASIL, 2012). Assim sendo, o caráter da proposta de ações de educação ambiental no âmbito do Projeto Casamar é interdisciplinar e coaduna com a Resolução CNE nº 2/2012 e com o PPP dos cursos.

Para a consecução do objetivo da pesquisa, o método documental desta investigação seguiu adaptação de Bardin (2011), que permite a análise de conteúdo considerando três 
etapas, a saber: pré-análise, exploração do material ou descrição analítica e uma terceira etapa de tratamento dos resultados e interpretação referencial. A aplicação da técnica análise de conteúdo de análise de dados qualitativos de base secundária seguiu o fluxograma descrito por Silva e Fossá (2015), conforme Figura 1.

Figura 1 - Fluxograma de análise de conteúdo

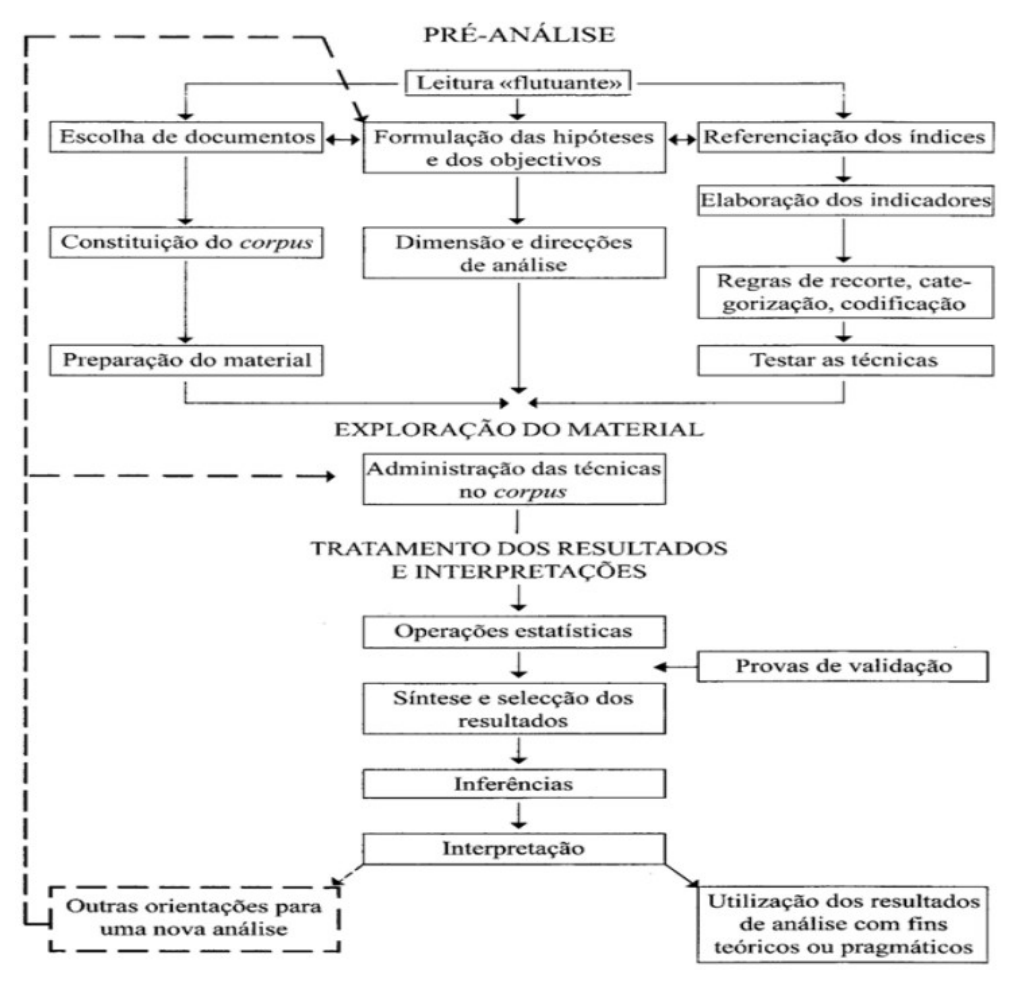

Fonte: Silva e Fossá (2015)

$\mathrm{Na}$ fase de pré-análise, obtiveram-se o quadro referencial teórico e o estabelecimento de indicadores para a interpretação das informações coletadas. Os relatórios do período de 2015 a 2019 de professores e alunos se configuraram na base de dados documental, e foram adquiridos, após o deferimento da solicitação ao coordenador do Projeto Casamar, o total de 20 relatórios digitais. O procedimento de pré-análise consistiu na leitura dos documentos para a identificação da representatividade, ou seja, quais relatórios apresentavam ações de educação ambiental. Assim, a amostragem final para esta investigação foram de 8 relatórios de estudantes que tiveram em comum a homogeneidade e o atendimento dos critérios estabelecidos, a saber: ações executadas entre 2015 e 2019, ações específicas em educação ambiental, ações aplicadas na Comunidade Villares da Serra e exercidas com público-alvo de crianças, jovens, mulheres e idosos, pois estes critérios têm pertinência com o que se propõe esta investigação de cunho 
em educação ambiental com vistas ao alcance dos Objetivos do Desenvolvimento Sustentável (ODS). Portanto, foram excluídos da amostra as ações de extensão e seus respectivos sujeitos, que não atenderam aos critérios de pertinência.

A segunda etapa desta pesquisa foi a exploração do material. Esta fase consiste na construção de operações de codificação, definição de regras, classificação e agregação das informações em categorias simbólicas ou temáticas (SILVA; FOSSÁ, 2015). Nesta etapa, a definição das categorias seguiu a orientação dos ODS, ou seja, foram utilizadas 17 categorias que coadunam com os 17 Objetivos do Desenvolvimento Sustentável, para que houvesse a possibilidade de consistência com a Agenda 2030.

A terceira e última etapa foi o tratamento dos resultados e sua interpretação, realizando-se análise comparativa, que, para Silva e Fossá (2015), é produzida por meio da justaposição das categorias existentes, ressaltando-se os aspectos de semelhanças e diferenças. No tratamento dos dados, o contexto educacional enfatizado disse respeito à experiência da ação extensionista no Projeto Casamar, se englobou o reconhecimento da atuação deste projeto correlacionado a programas internacionais, a exemplo dos Objetivos do Desenvolvimento Sustentável (ODS). Esse contexto educacional se relaciona com a ação 40 do Plano de Permanência e Êxito (PPE) do IFCE, que estabelece "ampliar e acompanhar o desenvolvimento de outros programas e ações que visem a melhoria da aprendizagem do estudante".

Em síntese, o percurso metodológico desta investigação foi:

1) leitura dos relatórios dos alunos e professores, período 2015 a 2019, da disciplina Projetos Sociais dos cursos do Departamento da Construção Civil, IFCE;

2) codificação das categorias temáticas em 17, em conformidade com os 17 ODS da Agenda 2030 para o Desenvolvimento Sustentável;

3) recorte do material coletado em consonância com ações de educação ambiental para público de crianças, jovens, mulheres e idosos;

4) tratamento dos resultados e análise comparativa;

5) interpretação dos resultados, análise, discussão e conclusões.

\section{Resultados e Discussão}

Após a primeira fase do método documental, foram identificadas as ações de extensão, com ênfase em educação ambiental, conforme o Quadro 1, o qual traz as informações do período realizado, quantidade de ações de extensão, ação específica na educação ambiental, número de alunos extensionistas com respectivo nível de ensino, quantidade de pessoas atingidas na comunidade e tipo de público-alvo na comunidade Villares da Serra. Ressalta-se que não houve acesso às informações dos semestres de 2017, considerando que não estavam disponíveis em formato digital. 
Quadro 1 - Síntese das informações sobre ações de extensão do Projeto Casa Maranguape, com ênfase em educação ambiental, no período de 2015 a 2019

\begin{tabular}{|c|c|c|c|c|c|}
\hline $\begin{array}{l}\text { Período } \\
\text { realizado }\end{array}$ & $\begin{array}{l}\text { Quantidade } \\
\text { de ações de } \\
\text { extensão } \\
\end{array}$ & $\begin{array}{l}\text { Ação específica em } \\
\text { educação ambiental }\end{array}$ & $\begin{array}{l}\text { Quantidade de } \\
\text { alunos/nível de ensino }\end{array}$ & $\begin{array}{l}\text { Quantidade } \\
\text { de pessoas/ } \\
\text { comunidade }\end{array}$ & $\begin{array}{c}\text { Tipo do } \\
\text { público-alvo }\end{array}$ \\
\hline 2015.1 & 2 & $\begin{array}{l}1 \text { - oficina de } \\
\text { reciclagem de papel }\end{array}$ & 2 / graduação & 10 & $\begin{array}{l}\text { Crianças e } \\
\text { jovens }\end{array}$ \\
\hline 2015.2 & 2 & $\begin{array}{l}1 \text { - visita ao } \\
\text { Planetário }\end{array}$ & $\begin{array}{l}6 \text { / graduação } \\
2 \text { / mestrado }\end{array}$ & 30 & $\begin{array}{l}\text { Crianças e } \\
\text { jovens }\end{array}$ \\
\hline \multirow[t]{2}{*}{2016.1} & \multirow[t]{2}{*}{2} & $\begin{array}{l}1 \text { - confecção de } \\
\text { carteira com uso de } \\
\text { tetrapak }\end{array}$ & $\begin{array}{l}2 \text { / graduação } \\
1 \text { / mestrado }\end{array}$ & 15 & $\begin{array}{l}\text { Mulheres e } \\
\text { idosos }\end{array}$ \\
\hline & & $\begin{array}{l}1 \text { - brinquedo } \\
\text { reciclado, bolhas de } \\
\text { sabão }\end{array}$ & 2 / graduação & 10 & Crianças \\
\hline \multirow[t]{2}{*}{2016.2} & \multirow[t]{2}{*}{2} & $\begin{array}{l}1 \text { - oficina de arte } \\
\text { com lixo }\end{array}$ & 2 / graduação & 10 & Crianças \\
\hline & & 1 - saúde coletiva & $\begin{array}{l}32 \text { / graduação, sendo } \\
13 \text { do IFCE e } 19 \text { da } \\
\text { UFC/Projeto Rondon }\end{array}$ & 60 & $\begin{array}{l}\text { Crianças, } \\
\text { jovens e } \\
\text { idosos }\end{array}$ \\
\hline \multirow[t]{2}{*}{2018.1} & \multirow[t]{2}{*}{2} & $\begin{array}{l}1 \text { - palestra sobre } \\
\text { sustentabilidade }\end{array}$ & $\begin{array}{l}13 \text { / graduação } 13 \\
\text { (sendo } 5 \text { do IFCE e } 8 \\
\text { do curso de } \\
\text { Arquitetura/FANOR) e } \\
2 \text { /mestrado. }\end{array}$ & 30 & $\begin{array}{l}\text { Crianças e } \\
\text { jovens }\end{array}$ \\
\hline & & $\begin{array}{l}1 \text { - visita técnica ao } \\
\text { Parque Estadual } \\
\text { Botânico de Caucaia }\end{array}$ & $\begin{array}{l}6 \text { / graduação } \\
4 \text { / mestrado }\end{array}$ & 25 & $\begin{array}{l}\text { Crianças e } \\
\text { jovens }\end{array}$ \\
\hline 2018.2 & 2 & $\begin{array}{l}1 \text { - palestra sobre } \\
\text { resíduos sólidos }\end{array}$ & 11 / graduação & 20 & $\begin{array}{l}\text { Crianças e } \\
\text { jovens }\end{array}$ \\
\hline 2019.1 & 1 & $\begin{array}{l}1 \text { - visita técnica ao } \\
\text { Projeto Casamar, } \\
\text { com ênfase em } \\
\text { tecnologias } \\
\text { alternativas de } \\
\text { construção para } \\
\text { moradia. }\end{array}$ & $\begin{array}{l}39 \text { / graduação (sendo } \\
14 \text { do IFCE e } 25 \text { do } \\
\text { curso de Engenharia } \\
\text { Civil da UFC Crateús). }\end{array}$ & 25 & $\begin{array}{l}\text { Crianças } \\
\text { jovens }\end{array}$ \\
\hline 2019.2 & 2 & 0 & -- & -- & -- \\
\hline Total & 15 & 10 & $\begin{array}{l}115 \text { alunos de } \\
\text { graduação (sendo } 63 \\
\text { alunos do IFCE e } 52 \text { de } \\
\text { parceiros) } \\
9 \text { alunos do Mestrado } \\
\text { PGTGA/IFCE }\end{array}$ & 235 & $\begin{array}{l}\text { Crianças, } \\
\text { jovens, } \\
\text { mulheres e } \\
\text { idosos. }\end{array}$ \\
\hline
\end{tabular}

Fonte: Autores, 2021. 
Foram atendidas 235 pessoas entre crianças, jovens, mulheres e idosos na Comunidade Villares da Serra, com envolvimento de 124 alunos extensionistas (alunos de graduação e de pós-graduação), no período de 2015 a 2019; o que totaliza o envolvimento de 359 pessoas. Os professores que conduziram as ações foram em número de 6 . A faixa etária das crianças e jovens da comunidade Villares da Serra estava entre 5 e 17 anos.

O Quadro 1 permite afirmar que a abordagem em educação ambiental prevaleceu em 10 de 15 ações, ou seja, 67\% das atividades de extensão no período analisado (2015-2019), o que coaduna com as orientações das Diretrizes Curriculares Nacionais para Educação Ambiental (BRASIL, 2012), bem como está em concordância com o disposto nos Planos Pedagógicos dos Cursos do IFCE e do PPI (IFCE, 2018).

Após a consecução da segunda etapa do método de análise, o Quadro 2 traz os resultados da relação das ações de educação ambiental do Projeto Casa Maranguape em relação às 17 categorias temáticas dos Objetivos do Desenvolvimento Sustentável, cuja categorização tem sombreamento com os próprios ODS da Agenda 2030. Este sombreamento de agregação ressalta o aspecto de transversalidade e de interdisciplinaridade da implementação dessa agenda global, conforme preceitua Raeder e Menezes (2019).

Quadro 2 - Aderência das ações de educação ambiental do Projeto Casamar aos Objetivos do Desenvolvimento Sustentável, no período de 2015 a 2019.

\begin{tabular}{|c|c|c|c|c|}
\hline $\begin{array}{l}\text { Ação específica em } \\
\text { educação ambiental }\end{array}$ & $\begin{array}{c}\text { Tipo do } \\
\text { público-alvo }\end{array}$ & Codificação do conteúdo da ação & $\begin{array}{l}\text { Categoria } \\
\text { do ODS }\end{array}$ & $\begin{array}{c}\text { Meta } \\
\text { específica do } \\
\text { ODS } \\
\end{array}$ \\
\hline $\begin{array}{l}\text { Oficina de } \\
\text { reciclagem de papel }\end{array}$ & $\begin{array}{l}\text { Crianças e } \\
\text { jovens }\end{array}$ & $\begin{array}{l}\text { Educação; resíduos sólidos; } \\
\text { minimização da poluição; } \\
\text { oportunidade de incremento de } \\
\text { renda; produção sustentável }\end{array}$ & $\begin{array}{l}\text { ODS } 4 \\
\text { ODS } 8 \\
\text { ODS } 12 \\
\text { ODS } 17\end{array}$ & $\begin{array}{l}\text { Meta } 4.4 \\
\text { Meta } 4.7 \\
\text { Meta } 8.6 \\
\text { Meta } 12.5 \\
\text { Meta } 17.16 \\
\end{array}$ \\
\hline Visita ao Planetário & $\begin{array}{l}\text { Crianças e } \\
\text { jovens }\end{array}$ & $\begin{array}{l}\text { Educação; sustentabilidade; } \\
\text { alterações climáticas; evolução da } \\
\text { Terra }\end{array}$ & $\begin{array}{l}\text { ODS } 4 \\
\text { ODS } 13 \\
\text { ODS } 17\end{array}$ & $\begin{array}{l}\text { Meta } 4.7 \\
\text { Meta } 13.13 \\
\text { Meta } 13 . b \\
\text { Meta } 17.16\end{array}$ \\
\hline $\begin{array}{l}\text { Confecção de } \\
\text { carteira com uso de } \\
\text { caixas tetrapak }\end{array}$ & $\begin{array}{l}\text { Mulheres e } \\
\text { idosos }\end{array}$ & $\begin{array}{l}\text { Educação; resíduos sólidos; } \\
\text { minimização da poluição; } \\
\text { oportunidade de incremento de } \\
\text { renda; consumo sustentável; } \\
\text { igualdade de gênero; crescimento } \\
\text { econômico sustentável e inclusivo }\end{array}$ & $\begin{array}{l}\text { ODS } 1 \\
\text { ODS } 4 \\
\text { ODS } 5 \\
\text { ODS } 8 \\
\text { ODS } 16 \\
\text { ODS } 17\end{array}$ & $\begin{array}{l}\text { Meta } 1.2 \\
\text { Meta } 4.4 \\
\text { Meta } 5.5 \\
\text { Meta } 8.6 \\
\text { Meta } 16.10 \\
\text { Meta } 17.16\end{array}$ \\
\hline $\begin{array}{l}\text { Brinquedo reciclado, } \\
\text { bolhas de sabão }\end{array}$ & Crianças & $\begin{array}{l}\text { Educação; resíduos sólidos; } \\
\text { minimização da poluição }\end{array}$ & $\begin{array}{l}\text { ODS } 4 \\
\text { ODS } 12 \\
\text { ODS } 17\end{array}$ & $\begin{array}{l}\text { Meta } 4.7 \\
\text { Meta } 12.5 \\
\text { Meta } 17.16\end{array}$ \\
\hline
\end{tabular}




\begin{tabular}{|c|c|c|c|c|}
\hline $\begin{array}{l}\text { Oficina de arte com } \\
\text { lixo }\end{array}$ & Crianças & $\begin{array}{l}\text { Educação; resíduos sólidos; } \\
\text { minimização da poluição; } \\
\text { consumo sustentável }\end{array}$ & $\begin{array}{l}\text { ODS } 4 \\
\text { ODS } 12 \\
\text { ODS } 17\end{array}$ & $\begin{array}{l}\text { Meta } 4.7 \\
\text { Meta } 12.5 \\
\text { Meta } 17.16\end{array}$ \\
\hline $\begin{array}{l}\text { Saúde coletiva } \\
\text { (Cuidados básicos } \\
\text { para o adulto e o } \\
\text { idoso; Instruções de } \\
\text { acompanhamento } \\
\text { para o tratamento de } \\
\text { doenças; higiene } \\
\text { oral e autoexame de } \\
\text { boca na prevenção } \\
\text { do câncer; atividade } \\
\text { de alongamento e } \\
\text { avaliação de risco) }\end{array}$ & $\begin{array}{l}\text { Crianças, } \\
\text { jovens e idosos }\end{array}$ & Vida saudável; educação; higiene & $\begin{array}{l}\text { ODS } 3 \\
\text { ODS } 17\end{array}$ & $\begin{array}{l}\text { Meta } 3.4 \\
\text { Meta } 3.5 \\
\text { Meta } 3 \mathrm{~d} \\
\text { Meta } 17.16\end{array}$ \\
\hline $\begin{array}{l}\text { Palestra sobre } \\
\text { sustentabilidade }\end{array}$ & $\begin{array}{l}\text { Crianças e } \\
\text { jovens }\end{array}$ & $\begin{array}{l}\text { Educação, gestão sustentável de } \\
\text { água e esgoto; minimização da } \\
\text { poluição }\end{array}$ & $\begin{array}{l}\text { ODS } 4 \\
\text { ODS } 6 \\
\text { ODS } 11 \\
\text { ODS } 12 \\
\text { ODS } 16 \\
\text { ODS } 17\end{array}$ & $\begin{array}{l}\text { Meta } 4.4 \\
\text { Meta } 4.7 \\
\text { Meta } 6 . b \\
\text { Meta } 11.4 \\
\text { Meta } 12.8 \\
\text { Meta } 16.6 \\
\text { Meta } 17.16\end{array}$ \\
\hline $\begin{array}{l}\text { Visita técnica ao } \\
\text { Parque Estadual } \\
\text { Botânico de Caucaia }\end{array}$ & $\begin{array}{l}\text { Crianças e } \\
\text { jovens }\end{array}$ & $\begin{array}{l}\text { Gestão de áreas protegidas; uso } \\
\text { sustentável dos recursos de fauna e } \\
\text { flora }\end{array}$ & $\begin{array}{l}\text { ODS } 4 \\
\text { ODS } 11 \\
\text { ODS } 13 \\
\text { ODS } 17\end{array}$ & $\begin{array}{l}\text { Meta } 4.7 \\
\text { Meta } 11.4 \\
\text { Meta } 13.3 \\
\text { Meta } 17.16\end{array}$ \\
\hline $\begin{array}{l}\text { Palestra sobre } \\
\text { resíduos sólidos }\end{array}$ & $\begin{array}{l}\text { Crianças e } \\
\text { jovens }\end{array}$ & $\begin{array}{l}\text { Educação, gestão sustentável; } \\
\text { minimização da poluição; cidades } \\
\text { com menos poluição }\end{array}$ & $\begin{array}{l}\text { ODS } 4 \\
\text { ODS } 8 \\
\text { ODS } 11 \\
\text { ODS } 12 \\
\text { ODS } 16 \\
\text { ODS } 17\end{array}$ & $\begin{array}{l}\text { Meta } 4.7 \\
\text { Meta } 11.4 \\
\text { Meta } 12.5 \\
\text { Meta } 12.8 \\
\text { Meta } 16.10 \\
\text { Meta } 17.16\end{array}$ \\
\hline $\begin{array}{l}\text { Visita técnica ao } \\
\text { Projeto Casamar, } \\
\text { com ênfase em } \\
\text { tecnologias } \\
\text { alternativas de } \\
\text { construção para } \\
\text { moradia. }\end{array}$ & $\begin{array}{l}\text { Crianças e } \\
\text { jovens }\end{array}$ & $\begin{array}{l}\text { Construções sustentáveis; moradia } \\
\text { digna e saudável; crescimento } \\
\text { econômico sustentável e inclusivo }\end{array}$ & $\begin{array}{l}\text { ODS } 4 \\
\text { ODS } 17\end{array}$ & $\begin{array}{l}\text { Meta } 4.7 \\
\text { Meta } 17.7\end{array}$ \\
\hline
\end{tabular}

Fonte: Autores, 2021.

Os resultados mostram que as ações de educação ambiental realizadas no período de 2015 a 2019 têm aderência com 11 dos 17 Objetivos do Desenvolvimento Sustentável, a saber: ODS 1, 3, 4, 5, 6, 8, 11, 12, 13, 16 e 17. Esses resultados reforçam e ampliam os encontrados por Silva e Cabral (2019, p.56), ao afirmarem que "a intervenção, por meio de 
ações de extensões, pode modificar ou conferir melhorias ao comportamento humano e mudanças de atitudes perante determinados assuntos”. É possível constatar que as ações de extensão exercidas no âmbito do Projeto Casa Maranguape têm uma característica de convergência de conhecimentos de diferentes especialidades, o que Kern et al. (2017) denominam ser característica típica da interdisciplinaridade e que Raeder e Menezes (2019) enfatizam ser esta interdisciplinaridade inerente ao desenvolvimento sustentável e, consequentemente, à Agenda 2030.

Assume-se que as ações analisadas neste artigo atendem às estratégias elencadas por Menezes (2018) no relatório do $3^{\circ}$ Encontro Nacional da Rede de ODS, a saber: realizar oficinas de formação sobre a Agenda 2030, tendo como público-alvo pessoas que possam ser multiplicadoras; focar em temas como educação, sustentabilidade e água, bem como a necessidade de as atividades desenvolvidas nos âmbitos das Instituições de Pesquisa, Extensão, Tecnologia e Inovação abordarem os princípios da Agenda 2030. Assume-se, ainda, que os resultados encontrados convergem com o que dispõem Brasil (2017) e IDS (2019).

A terceira etapa de análise realizada nesta investigação foi o tratamento dos dados, por meio de análise comparativa com enfoque no contexto educacional, sobre se a experiência da ação extensionista no Projeto Casamar englobou a atuação relacionada a programas internacionais, a exemplo dos Objetivos do Desenvolvimento Sustentável (ODS). Essa relação pode ser observada no Quadro 2 e na Figura 2.

Figura 2 - Análise comparativa das ações de extensão do Projeto Casa Maranguape no contexto educacional com relação aos Objetivos do Desenvolvimento Sustentável

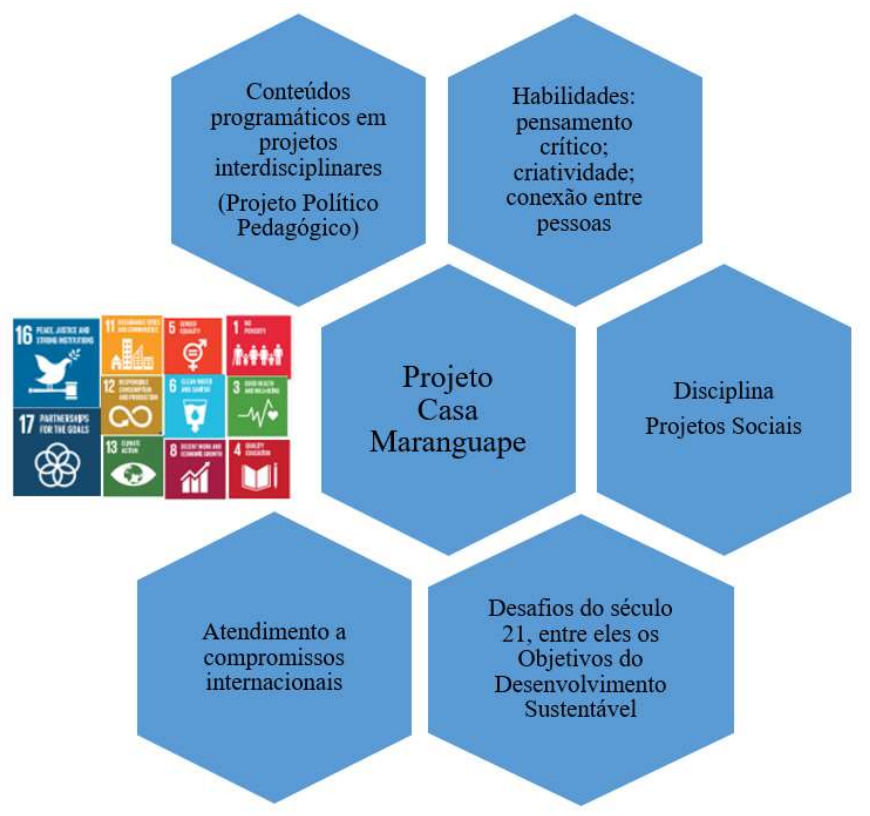

Fonte: Elaborado pelos autores. 
Os resultados mostram que as experiências estudantis no contexto educacional das ações de extensão englobaram uma atuação relacionada à Agenda 2030 de Desenvolvimento Sustentável, que traz os 17 ODS como um importante processo aberto, inclusivo e transparente, com foco na promoção da prosperidade e da paz, por meio da implementação de parcerias entre pessoas e instituições. Houve reflexão positiva dos estudantes sobre ações acadêmicas de extensão que podem levar a mudanças benéficas e intervenções positivas em moradores da comunidade Villares da Serra, local de execução do programa de extensão.

As repercussões deste artigo respondem positivamente sobre o papel da extensão no processo de ensino e aprendizagem dentro de instituições de Educação Profissional e Tecnológica, de modo específico no Instituto Federal de Educação, Ciência e Tecnologia do Ceará, na medida em que confirmam a articulação entre a tríade ensino, pesquisa e extensão como uma política para expandir o conhecimento e preceituam a integração de conhecimentos para responder a questões complexas e sistêmicas, que demandam interdisciplinaridade na sua execução.

As contribuições da prática docente de vivência do Projeto Casamar permitem afirmar a territorialização e localização dos ODS no contexto educacional de instituições de EPT, com reflexo na consecução de uma agenda de desenvolvimento sustentável.

\section{Conclusões}

O que se destaca neste artigo é o reconhecimento de que existe, no âmbito do Projeto Casa Maranguape (Projeto Casamar), o fortalecimento das ações contínuas que promovem orientações aos estudantes sobre a importância de atividades extracurriculares para o exercício profissional e para o desenvolvimento de habilidades com pensamento crítico, com o objetivo de enfrentar os desafios do século XXI. Considerando as dificuldades, tais como ausência de recursos financeiros para execução das ações e de transporte para os estudantes se deslocarem à Comunidade Villares da Serra, é neces-sário seu fortalecimento como atividade extracurricular vinculada ao eixo da extensão.

Infere-se que o Projeto Casamar demonstrou estar fortemente alinhado aos Objetivos do Desenvolvimento Sustentável, considerando que $67 \%$ das ações executadas no período de 2015 a 2019 representam ações em educação ambiental com compromisso à consecução dos ODS e da Agenda 2030 para o Desenvolvimento Sustentável.

Considera-se, ainda, que o Projeto Casamar conduz melhoria na prática docente e acadêmica por direcionar consciência ambiental, social e política na formação da cidadania dos jovens aprendizes. O Projeto Casamar se mostrou um catalisador de construção de cidadania, intervindo positivamente na mudança de comportamento ambiental em 235 crianças, jovens, mulheres e idosos da Comunidade Villares da Serra, considerado o período analisado (20152019). 
As questões ambientais e as metas estabelecidas nos ODS podem, particularmente, representar o caminho orientador para o redesenho de um quadro institucional na Educação Profissional e Tecnológica, que amplie a participação dos estudantes na extensão, valorizando uma dinâmica que priorize o desenvolvimento local e regional, a exemplo do que o Projeto Casamar realiza, cujos resultados positivos são evidenciados neste artigo. Isso corresponde, também, à visão holística, plural e estratégica que o saber docente exige na formação profissional e tecnológica para o necessário enfrentamento aos desafios de desenvolvimento.

\section{Referências}

ALVES, Rubem. Por uma Educação romântica. 8. ed. Campinas: Papirus, 2009. p. 29-32.

BARDIN, Laurence. Análise de Conteúdo. Lisboa: Edições 70, 2011.

BRASIL. Resolução CNE $n^{0}$ 2, de 15 de junho de 2012, que dispõe sobre as Diretrizes Curriculares Nacionais para Educação Ambiental. Diário Oficial da União, Brasília, DF, 2012.

\section{BRASIL. Relatório Nacional Voluntário sobre os Objetivos do Desenvolvimento}

Sustentável. Brasília: Secretaria de Governo da Presidência da República/Ministério do Planejamento, Desenvolvimento e Gestão, 2017.

BIERMANN, Frank; KANIE, Norichika; KIM, Rakhyun E. Global governance by goalsetting: the novel approach of the UN Sustainable Development Goals. Current Opinion in Environmental Sustainability, v. 26-27, p.26-31, 2017.

CABRAL, Nájila Rejanne Alencar Julião; SILVA, Adeildo Cabral. Ações de educação ambiental no Projeto Casa Maranguape. Revista Expressões da Extensão, v.3. n.2, p. 68$72,2018$.

CNODS - Comissão Nacional para os Objetivos do Desenvolvimento Sustentável. Relatório de Atividades 2017-2018. Brasília: CNODS, 2018.

GIUSTA, Ângela da Silva. Concepções de aprendizagem e práticas pedagógicas. Educação em Revista, v. 29, n. 1, p. 17-36, 2013.

HÁK, Tomás; JANOUSKOVÁ, Svatava; MOLDAN, Bedrich. Sustainable Development Goals: A need for relevant indicators. Ecological Indicators, v. 60, p. 565-573, 2016. 
IDS - Instituto Democracia e Sustentabilidade. III Relatório Luz da Agenda 2030 de Desenvolvimento Sustentável Brasil. São Paulo: IDS/ Grupo de Trabalho da Sociedade Civil para Agenda 2030, 2019.

IFCE - Instituto Federal do Ceará. Projeto Político Institucional do Instituto Federal do Ceará. Fortaleza: IFCE, 2015.

IFCE - Instituto Federal do Ceará. Plano Estratégico de Permanência e Êxito dos Estudantes 2017-2024 do IFCE. Fortaleza: IFCE, 2017.

IFCE - Instituto Federal do Ceará. Projeto Político-pedagógico Institucional do Instituto Federal do Ceará. Fortaleza: IFCE, 2018.

IPEA - Instituto de Pesquisa Econômica Aplicada. Agenda 2030 Objetivos do Desenvolvimento Sustentável: proposta de metas Brasileiras. Brasília: IPEA, 2018.

KERN, Vinícius M.; MALDONADO, Maurício Uriona; FREIRE, Patrícia de Sá; PACHECO, Roberto C.S. Construção da interdisciplinaridade para a inovação. In: PHILIPPI Jr., Arlindo; FERNANDES, Valdir; PACHECO, Roberto C. S. Ensino, Pesquisa e Inovação: Desenvolvendo a Interdisciplinaridade. Capítulo 26. Barueri, SP: Manole, 2017. p. 743-767.

MASETTO, Marcos T. Docência no ensino superior voltada para a aprendizagem faz a diferença. São Paulo: USP/Mackenzie, 2010, 38p. Disponível em: http://www.prpg.usp.br/attachments/article/640/Caderno_12_PAE.pdf. Acesso em: 17 set. 2019.

MENEZES, Patrícia M. (Org.). Relatório Final do $3^{\mathbf{0}}$ Encontro Nacional da Rede ODS Brasil. Brasília: 2018. Disponível em http://repositorio.enap.gov.br/handle/1/3249. Acesso em: 17 set. 2019.

MINAYO, M. C. S. O desafio do conhecimento: pesquisa qualitativa em saúde. 8 . ed. São Paulo: Hucitec, 2004.

ONU - Organização das Nações Unidas. Transformando Nosso Mundo: A Agenda 2030 para o Desenvolvimento Sustentável. Nova Iorque: ONU, 2015. Disponível em: https://sustainabledevelopment.un.org/post2015/transformingourworld/publication. Acesso em: 27 fev. 2020.

PNUD - Programa das Nações Unidas para o Desenvolvimento. Transformando Nosso Mundo: a Agenda 2030 para o Desenvolvimento Sustentável. Brasília: PNUD, 2019. 
PNUD - Programa das Nações Unidas para o Desenvolvimento. Programas de capacitação em territorialização dos ODS serão em formato virtual. Disponível em: https://www.br.undp.org/. Acesso em: 02 out. 2020.

RAEDER, Sávio Túlio Oselieri; MENEZES, Patrícia Miranda. A relação entre interdisciplinaridade e a implementação da Agenda 2020. Revista Parcerias Estratégicas, v. 24, n. 49, p. 9-28, 2019.

SILVA, Adeildo Cabral; CABRAL, Nájila Rejanne Alencar Julião. Projeto Casa Maranguape: Inclusão Social - Educação Profissional para Geração de Emprego e Renda. In: The World Forum of Vocational and Technological Education (FMEPT), Florianópolis, 2012.

SILVA, Adeildo Cabral; CABRAL, Nájila Rejanne Alencar Julião. Análise das ações de extensão do Projeto Casamar correlacionadas aos Objetivos do Desenvolvimento Sustentável. Revista Compartilhar, v.3, n.1, p. 53-57, 2019.

SILVA, Andressa Henning; FOSSÁ, Maria Ivete Trevisan. Análise de conteúdo: exemplo de aplicação da técnica para análise de dados qualitativos. Qualit@s Revista Eletrônica, v.16, n. 1, p. 1-14, 2015.

TARDIF, Maurice. Os professores diante do saber: esboço de uma problemática do saber docente. In: TARDIF, Maurice. Saberes docentes e formação profissional. Petrópolis: Vozes, 2014. p.31-55. 